\title{
Analysis of the Efficiency of Circuits using Natural Gas Additional Energy Potentials on Cogenerating Boiler Houses with Internal Combustion Engines
}

\author{
A.G. Arzamascev, A.I. Sharapov, A.V. Peshkova
}

\begin{abstract}
The article studies the energy efficiency of various circuits using the energy of natural gas excessive pressure in expander-generator units installed before gas reciprocating engines in cogeneration boiler houses. The circuits with and without gas heating before the expander are considered. As an energy effect from the expander use at the cogeneration boiler house fuel economy is taken as compared with the circuits with gas throttling with constant production schedules of electrical and thermal power. The dependence on specific fuel economy determination is obtained. For the circuits being compared, the areas of the energy effect magnitude dependence on the outside temperature are allocated. It is shown that the circuit with heated gas before the expander will have the greatest energy effect at the outside air temperature up to the value corresponding to the equal values of specific fuel economy for the considered circuits and with disconnection of gas heating at higher air temperatures. The method proposed in the paper can be used to calculate the energy effect from various circuits of the expander application in cogeneration boiler houses with internal combustion engine both in exisiting ones and the ones which are under design.
\end{abstract}

Index Terms: expander-generator set, cogeneration boiler house, energy efficiency.

\section{INTRODUCTION}

Currently, the problem of introducing resource-saving technologies in the energy sector is particularly relevant. A promising direction is construction of cogeneration boiler houses, which have combined heat and power generation. The main advantage of cogeneration is reduction in fuel consumption compared with generation of the same amount of the energy product in a separate way, which reduces the unit cost of production. Electric energy production in the cogeneration boiler house covers both the own needs of the boiler house and consumer needs, which makes it possible to exclude costs for electricity purchase from outside. At the

Revised Manuscript Received on July 09, 2019.

A.G. Arzamascev, Lipetsk State Technical University, Lipetsk, Russia

A.I. Sharapov, Lipetsk State Technical University, Lipetsk, Russia

A.V. Peshkova, Lipetsk State Technical University, Lipetsk, Russia same time, small distances between the consumer and energy-generating equipment of the boiler house make it possible to virtually eliminate losses in electricity transmission to consumers. Thus, application of the cogeneration principles allows you to improve the economic performance of the energy company.

Cogeneration boiler-houses are essentially mini-CHPs, while the values of generated heat and electric power are comparable. With electric power up to $5 \mathrm{MW}$, the most promising are boiler houses with gas reciprocating internal combustion engines (ICE) [1].

Improving the energy efficiency of such boiler houses allows saving natural fuel and reducing emissions to the environment. When burning a fuel in an internal combustion engine, only its chemical energy is useful. One of the options for increasing efficiency is the use of additional energy potentials of natural gas and domestic energy resources of the boiler house.

Natural gas is classified as a combustible energy resource, as its greatest energy potential is the heat of combustion released during combustion. The fuel calorific value is determined by the fuel chemical composition. In modern boiler houses only the part of the heat from natural gas combustion is used.

The gas coming to the boiler house has excessive pressure, the value of which can vary from 0.6 to $1.2 \mathrm{MPa}$ [2]. Before internal combustion engines, the gas is throttled which results in its pressure decrease to the values slightly higher than the atmospheric pressure, but the gas pressure energy is not useful. The energy potential of using excess gas pressure is significantly inferior to the combustion heat, but its use allows improving energy performance of the boiler house. The standard variant of using the potential energy of the natural gas excessive pressure for generation of electricity at energy companies is installation of expander-generating units (EGU) before the fuel-burning equipment [3-12]. 


\section{Analysis of the Efficiency of Circuits using Natural Gas Additional Energy Potentials on Cogenerating Boiler Houses With Internal Combustion Engines}

There is a number of papers [13-19] devoted to the aspects of EGU operation in energy-producing enterprises. Since gas-piston boiler houses have combined generation of heat and electricity, combined heat and power plants (CHP) are energy enterprises closest in their purpose to the cogeneration boiler house. When using EGU at CHP, lowering the gas temperature impairs the efficiency of the main equipment of the steam-turbine cycle, which requires preheating of the gas before the expander. The internal combustion engine efficiency, on the contrary, increases with decrease in the fuel mixture temperature, which makes the method for calculating the energy effect from EGU use at large CHP plants not applicable when determining the energy effect from EGU use in cogeneration boiler houses. The gas heating before the expander increases the specific useful work of EGU, but may adversely affect the internal combustion engine operation.

In order to optimize operation of the engine, it has been proposed to maintain the fuel mixture temperature not higher than the optimum value using a refrigerating machine. In this case, ICE works with maximum efficiency and the magnitude of ICE specific work is constant.

In the article [12], there is an investigation of the operation mode of cogeneration boiler houses with EGU, taking into account reduction of the specific performance of the internal combustion engine at air temperature increase. In this paper, we consider only one option that is without gas heating before the expander. In this case, the expander allows you to extend the engine operation mode with the maximum efficiency. However, after a certain air temperature for the circuit with an expander, the specific performance of the engine will also begin to decrease. At temperatures of the fuel mixture above the maximum allowable value for this type of engine, the chiller, cooling the mixture to the maximum allowable temperature turns on. The considered operation mode of the boiler house equipment is not optimal, since the engine does not work with the maximum effective work output.

The literature analysis shows lack of studies on comparison of the energy efficiency from the use of various circuits with EGU in cogeneration boilers with internal combustion engines.

The purpose of this article is to propose a method for calculating the energy effect of EGU application in cogeneration boiler houses with gas piston internal combustion engines for optimal operation of the boiler house equipment and analysis of the energy efficiency of various EGU application circuits.

\section{ENERGY EFFICIENCY EVALUATION OF CIRCUITS WITH EGU}

Installation of expander-generator units before fuel-burning units allows electricity due to the beneficial use of gas overpressure to increase the total specific useful work of the boiler house for generating electricity.

The expander-generator unit consists of an expander and an electric generator connected to it, as well as necessary auxiliary equipment. The gas pressure energy entering the expander is used to generate mechanical work, which is then converted into electrical energy in the generator. The expander allows you to get electrical energy without burning fuel, which makes it possible to reduce the unit cost of electrical power. In further calculations it is assumed that the electricity generated by the expander generator unit and internal combustion engine at the cogeneration boiler house enters into one common network, from which it is distributed among consumers.

Let us assume that all gas consumed by the boiler house enters the internal combustion engine (ICE), while the thermal load is covered by using the heat of ICE exhaust gases in the heat recovery unit.

Increasing the useful work output on electricity generation of an energy company can be used to increase power with constant fuel consumption or to reduce fuel consumption while maintaining the same generation of total electric power. The energy effect of the circuit with EGU application at the cogeneration boiler house lies in fuel economy compared to the circuit with gas throttling before fuel-burning units with constant schedules for generating electrical and thermal power. The use of an expander generator unit providing constancy of the schedule for electric power generation also reduces electrical load on the internal combustion engine by no more than $1-2 \%$ compared with the throttled circuit. Since the value of efficiency of modern ICE at the values of electrical load being more than $50 \%$ of the nominal one practically does not change, you can ignore the effect of load changes from the use of an expander generator unit on the efficiency factor of ICE for power generation.

At the same time, natural gas can be considered as pure methane and gas expansion in the expander can be calculated using formulas for ideal gas, taking into account expander efficiency [20-21]. To estimate the energy effect, we use the values of specific useful works, reduced to a unit of the natural gas volume consumed by a boiler house.

EGU specific useful work is:

$$
\begin{aligned}
& l_{\mathrm{EGU}}=c_{\mathrm{p}}^{\prime} \cdot\left(T_{\mathrm{g} \text {.inl }}-T_{\mathrm{g} \text {.out }}\right) \cdot \eta_{\mathrm{EM} .}= \\
& =c_{\mathrm{p}}^{\prime} \cdot T_{\mathrm{g} \text {.inl }} \cdot\left[1-\left(\frac{P_{\mathrm{g} . \text { out }}}{P_{\mathrm{g} . \text {.inl }}}\right)^{\frac{\mathrm{k}-1}{\mathrm{k}}}\right] \cdot \eta_{\text {exp. }} \cdot \eta_{\mathrm{EM}} \\
& \text { where } \quad P_{\text {g.inl }}, P_{\mathrm{g} \text {.out }}-
\end{aligned}
$$
gas pressure at the inlet to and out of the expander, respectively,

$\mathrm{Pa}$; 
$T_{\mathrm{g} \text {.inl }}, T_{\mathrm{g} \text {.out }}-$ for actual process of expansion of the gas temperature at the inlet to and out of the expander, respectively, $\mathrm{K} ; k-$ gas adiabat index; $\eta_{\text {exp. }}$ - internal relative efficiency of the expander; $\eta_{\mathrm{EM}}$-electromechanical efficiency EGU; $c_{p}^{\prime}$ - isobaric volumetric heat capacity of gas, $J /\left(n . m^{3} \cdot K\right)$. For circuits with EGU without heating: $T_{\text {g.inl }}=T_{\text {gas. } 0}$, where $T_{\text {gas. } 0}-$ gas temperature at the boiler house inlet, $\mathrm{K}$.

ICE specific useful work is:

$$
l_{\mathrm{ICE}}=Q_{v}^{l} \cdot \eta_{I C E}
$$

where $Q_{v}^{l}-$ lower calorific value of fuel, J/n.m ${ }^{3}$; $\eta_{I C E}-$ efficiency ICE for power generation.

The efficiency of gas-piston IEC for generation of electrical energy depends on the fuel mixture temperature at the engine inlet. The maximum value of efficiency is maintained in the fuel mixture temperature range from the minimum permissible to the optimum. The efficiency of ICE decreases with increase in the temperature of the mixture from the optimum to the maximum permissible. To prevent automatic shutdown of the engine when the mixture temperature rises above the maximum permissible value, switching on of a vapor compression refrigerating machine for the fuel mixture cooling is provided.

We take the temperature of the gas entering the boiler house equal to the outside air temperature, which allows the mixture temperature to be considered equal to the air temperature for the circuit with throttling.

The fuel mixture temperature when using EGU will be determined by the formula:

$$
l_{\mathrm{mix}}=\frac{\rho_{\mathrm{gas}} \cdot c_{\mathrm{gas}} \cdot t_{\mathrm{gas}}+\bar{V}_{\mathrm{air}} \cdot \rho_{\mathrm{air}} \cdot c_{\text {air }} \cdot t_{\text {air }}}{\rho_{\mathrm{gas}} \cdot c_{\mathrm{gas}}+\overline{\bar{V}}_{\text {air }} \cdot \rho_{\text {air }} \cdot c_{\text {air }}}
$$

where $\rho_{\text {gas }}, \rho_{\text {air }}-$ densities under normal conditions of gas and air, respectively, $\mathrm{kg} / \mathrm{m}^{3} ; c_{\text {gas }}, c_{\text {air }}$ - specific mass isobaric heat capacities of gas and air, respectively, $\mathrm{J} /(\mathrm{kg} \mathrm{K})$; $t_{\text {gas }}, t_{\text {air }}-$ gas and air temperatures, respectively, ${ }^{\circ} \mathrm{C} ; \bar{V}_{\text {air }}-$ actual air consumption required for burning $1 \mathrm{n} . \mathrm{m}^{3}$ of gas, $\mathrm{n} . \mathrm{m}^{3} / \mathrm{n} \cdot \mathrm{m}^{3}$.

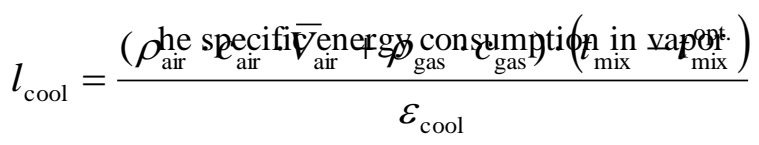

where $\varepsilon_{\text {cool }}-$ coefficient of performance; $t_{\text {mix }}^{\text {opt. }}-$ optimum temperature of the fuel mixture, ${ }^{\circ} \mathrm{C}$.

The gas temperature during expansion in the expander decreases, which allows reducing the unit cost of electricity for cooling the fuel mixture in the chiller or in some cases to ensure cooling of the mixture only by expander. The energy effect of full or partial replacement of an expander with a chiller depends on the value of the coefficient of performance (cooling factor). The higher the value of the coefficient of performance (cooling factor) is, the lower the magnitude of the energy effect from the replacement of a chiller with an expander is.

The value of the useful total electrical power for the option with throttling is proposed to be found as:

$$
N_{\Sigma}^{\text {thrtl. }}=G_{\Sigma}^{\text {thrtl. }} \cdot\left(l_{\text {ICE }}-l_{\text {cool }}^{\text {thrtl. }}\right)
$$

where $G_{\Sigma}^{\text {thrtl }}-$ total flow rate of the fuel supplied to ICE for the circuit with throttling, $\mathrm{n} . \mathrm{m}^{3} / \mathrm{s} ; l_{\mathrm{ICE}}, l_{\mathrm{cool}}^{\text {thrtl. }}-$ for the circuit with throttling, specific useful work of ICE and specific cost of electricity for the fuel mixture cooling, respectively, $\mathrm{J} / \mathrm{n} \cdot \mathrm{m}^{3}$.

The value of the useful total electric power for the option with EGU is proposed to be calculated by the formula:

$$
N_{\Sigma}^{\mathrm{EGU}}=G_{\Sigma}^{\mathrm{EGU}} \cdot\left(l_{\mathrm{EGU}}+l_{\mathrm{ICE}}-l_{\mathrm{cool}}^{\mathrm{EGU}}\right)
$$

where $G_{\Sigma}^{\mathrm{EGU}}$ - flow rate of the fuel entering the boiler house for the circuit with EGU, n.m ${ }^{3} / \mathrm{s} ; l_{\mathrm{ICE}}^{\mathrm{EGU}}, l_{\text {cool }}^{\mathrm{EGU}}-$ for the circuit with EGU, specific useful work of ICE and specific cost of electricity for the fuel mixture cooling, respectively, $\mathrm{J} / \mathrm{n} \cdot \mathrm{m}^{3} ; l_{\mathrm{EGU}}-$ specific useful work of EGU, J/n.m $\mathrm{m}^{3}$.

Then we suggest defining fuel economy as:

$$
\Delta G=G_{\Sigma}^{\text {thrtl. }}-G_{\Sigma}^{\mathrm{EGU}}
$$

Fuel economy allows you to determine the energy efficiency of the expander generator unit use at a particular boiler house. To carry out a summary analysis of the energy efficiency of using circuits with EGU on cogeneration boilers with different electric capacity, it is necessary to use specific criteria. Application of specific criteria allows selecting optimal circuits with EGU and their modes of operation for boiler houses of various capacities.

To analyze application of circuits with EGU in boiler houses with different electric capacity, it is necessary to use a specific parameter. As such a parameter, we will take the specific fuel economy equal to the ratio of fuel economy to fuel consumption for the circuit with throttling.

Specific fuel economy in this case:

$$
\Delta \bar{G}=\frac{\Delta G}{G_{\Sigma}^{\text {thrtl. }}}=\frac{l_{\mathrm{EGU}}+\left(l_{\mathrm{cool}}^{\text {thrtl. }}-l_{\mathrm{cool}}^{\mathrm{EGU}}\right)}{l_{\mathrm{EGU}}+l_{\mathrm{ICE}}-l_{\mathrm{cool}}^{\mathrm{EGU}}} \cdot 100 \%
$$

\section{THE ENERGY EFFECT OF CIRCUITS USING EGU}

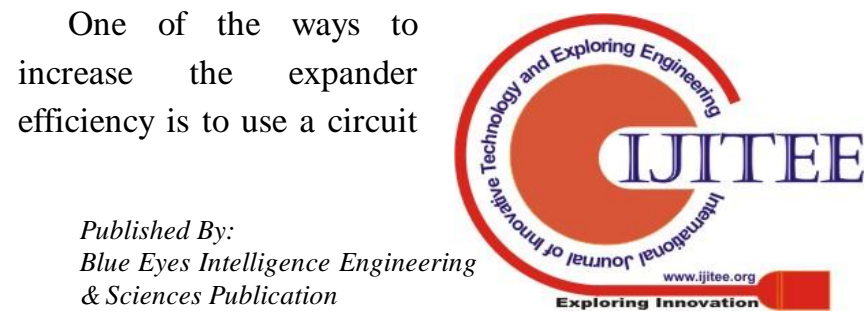




\section{Analysis of the Efficiency of Circuits using Natural Gas Additional Energy Potentials on Cogenerating Boiler Houses With Internal Combustion Engines}

with heated fuel before the expander or between its stages, which allows increasing the EGU specific work. The heater, located after the expander, does not affect EGU performance, but may adversely affect operation of the internal combustion engine during high air temperatures. It should be noted that it is not possible to completely avoid heating the gas in the circuit of the boiler house, since the mixture shall be heated to the minimum allowable temperature for this type of internal combustion engines.

When organizing natural gas heating, the first priority is to choose a source of heating, which is based on a number of different factors.

The main parameter determining the calorific value of heating is the final temperature of natural gas heating. The highest heating temperatures can be obtained by burning fuel. Use of additional fuel as a heat carrier seems impractical because it requires an increase in fuel consumption.

Further, we will consider heating the fuel only due to the heat of the internal energy resources of a boiler house, which makes it possible to disregard the heat from heating when determining the magnitude of the energy effect.

When burning natural gas with an air excess factor of $n=$ 1.1 per $1 \mathrm{~m}^{3}$ of natural gas, there are about $10-11 \mathrm{~m}^{3}$ of flue gases. The gas temperature at the exit of the internal combustion engine is significantly higher than the dew point temperature, and the change in flue gas temperature in the preheater is 10 to 15 times less than the similar change in natural gas temperature, which allows using flue gases as a source of preheating without fear of low temperature corrosion.

The heat carrier of ICE cooling system can also be considered as a heat source for gas heating. However, flue gases make it possible to achieve higher heating temperatures than the heat carrier of the cooling system. In addition, during the heating period, the heat carrier of ICE cooling system is used in cogeneration boiler houses to cover thermal loads, which makes it difficult to use it for heating gas.

Let us consider location of a preheater before the expander and between its stages. A more preferred option is to install a preheater before the expander while maintaining a constant gas temperature at the heat exchanger exit. With the same heating temperature, preheating has several advantages over the option of installing an intermediate heater: 1) the total specific work of the expander does not depend on the initial gas temperature, it is determined only by the heating temperature; 2) the gas temperature at the expander exit will be minimal compared with the option of using intermediate heating, which provides the maximum economy of electrical energy for cooling the mixture; 3 ) on condition that the fuel is heated to the same temperature, the preheating option has the smallest heat exchanger area with all other things being equal, since heating of the gas, which is already cooled in the first stage of the expander, to the heating temperature requires a higher heat output than heating the gas entering the boiler house.

Thus, according to the analysis of the possible options for heating it seems that the most optimal circuit is the one with natural gas heating before the expander due to the heat of ICE exhaust gases.

The disadvantage of heating is a rise of the gas temperature after the expander, which results in an increase in consumption of electricity for cooling the fuel mixture during the period of high outdoor temperatures.

Comparison of the energy capabilities of the heated and non-heated circuits makes it possible to assess the energy feasibility of gas heating. In the presence of the energy effect from the use of heating, the energy analysis makes it possible to assess the need to turn off the heating for reasons of energetic expediency and determines temperature ranges for operation of the circuit with the heating being turned off.

When calculating in the future we accept the following assumptions: The efficiency values of ICE are taken on the basis of the data on operation of "Caterpillar G3516" engine : the optimum efficiency value of ICE is $38 \%$ in the temperature range of the fuel mixture from $-30^{\circ} \mathrm{C}$ (minimum allowable temperature) to $+25^{\circ} \mathrm{C}$ (optimum temperature), at mixture temperatures from $+25{ }^{\circ} \mathrm{C}$ to $+35{ }^{\circ} \mathrm{C}$ (maximum allowed temperature) a linear decrease in the efficiency factor to a minimum value of $36 \%$ is taken. The value of the internal relative efficiency of the expander is taken to be $75 \%$, of the electromechanical efficiency $-97 \%$ [22].

For schemes using preheating, the gas temperature at the expander inlet was assumed to be $+100^{\circ} \mathrm{C}$, and in the absence of preheating, the input gas temperature was considered to be equal to the ambient air temperature. The coefficient of excess air when burning fuel in internal combustion engines is adopted as 1.1.

When calculating the coefficient of performance (cooling factor), the following conditions were given: Freon R22 is used as a refrigerant, the vapour temperature in the condenser is assumed to be $60^{\circ} \mathrm{C}$, the vapour temperature in the evaporator is $5^{\circ} \mathrm{C}$, efficiency of the refrigerating machine compressor is assumed to be 0.7 [23]. It is assumed that regulation of the cooling capacity is carried out only by changing the flow rate of the refrigerant at constant values of the other parameters, which suggests that the value of the coefficient of performance (cooling factor) remains constant. Using $\mathrm{h}-\mathrm{p}$ diagram for R22 Freon, we found the parameters of the main points of the refrigeration cycle, the magnitude of which let us determine the value of the coefficient of performance (cooling factor) which is, under these conditions, equal to 3 .

The absolute gas pressure at the expander inlet varies from 7 to 13 bar, 
the output pressure is 1.2 bar, the initial gas temperature for the circuits with throttling and without heating is assumed to be equal to the ambient air temperature. Gas pressure losses in the heat exchanger-heater can be neglected.

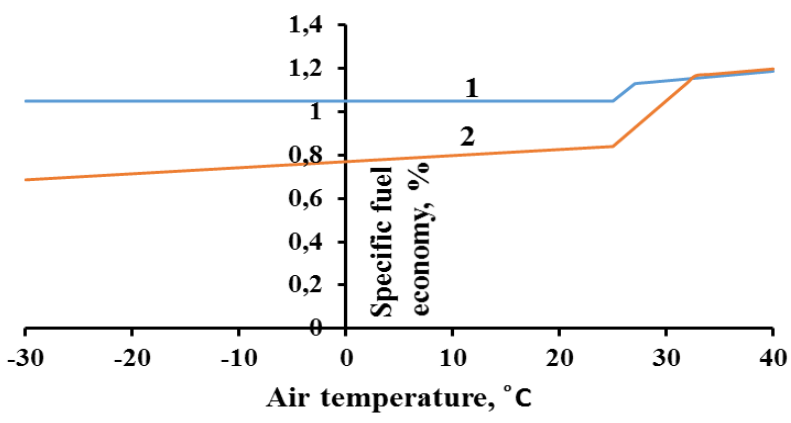

Fig.1. Dependence of the specific fuel economy on the outdoor temperature for the circuit with EGU at the initial pressure of 7 atm.: 1 - with preheating; 2 - without preheating.

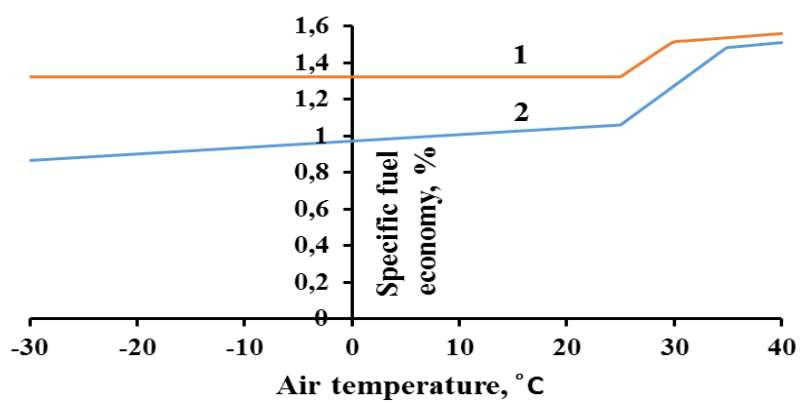

Fig.2. Dependence of the specific fuel economy on the outdoor temperature for the circuit with EGU at the initial pressure of 13 atm.: 1 - with preheating; 2 - without preheating.

Dependence of the energy effect on the outdoor temperature can be divided into 3 conditional areas:

1) The outdoor temperature is less than the optimum mixture temperature. In this case, a refrigerating machine for the circuits with EGU and throttling does not work, and the specific fuel economy is determined only by operation of the expander. The circuit with heating in this area has advantages due to the greater specific work of EGU.

2) The value of the outside air temperature is above the optimum temperature of the mixture, but below the air temperature, allowing the mixture temperature for the circuit with EGU to be maintained not more than the optimum temperature for this ICE. In this case, a refrigerating machine for the throttling circuit is turned on, and the specific fuel economy is determined not only by operation of the expander, but also by saving on electricity costs for the mixture cooling. This area is characterized by a maximum rate of increase in fuel economy with increasing air temperature. In saving the cost of the mixture cooling, the circuit with heating in this area is inferior to the circuit without heating, but due to the greater specific work of EGU, it ultimately benefits in the specific fuel economy. The difference in the values of specific fuel economy for the considered circuits with EGU decreases with increasing the air temperature.

3) The outdoor air temperature is higher than the value that allows providing the mixture temperature not higher than the optimum value for EGU circuits.. Up to the values of a certain air temperature, determined by the equality of the specific fuel economy for the considered circuits with EGU, the circuit with preheating gives a greater energy effect. With further increase in the air temperature, the circuit without heating gives a greater effect. The air temperature, at which the specific fuel economy values are compared for a circuit without heating and an option with heating, increases with a rise in initial gas pressure at the expander inlet: for the initial gas pressure of $7 \mathrm{~atm}$., its value is $32^{\circ} \mathrm{C}$, and for the initial gas pressure of $13 \mathrm{~atm}$. it exceeds $40^{\circ} \mathrm{C}$.

Thus, the energy effect of EGU application at cogeneration boiler houses depends on the outdoor temperature. With the exception of the hottest summer days, the use of gas heating before the expander allows increasing the total energy effect due to increase in the specific work of EGU. The specific fuel economy depending on the outdoor temperature for the circuits under consideration is within $0.65-1.2 \%$ for the pressure of $7 \mathrm{~atm}$. and $0.85-1.6 \%$ for the pressure of $13 \mathrm{~atm}$. , which suggests an increase in the energy efficiency of cogeneration boiler houses due to use of gas pressure energy in expander-generator units. It is shown that an increase in the inlet pressure has a positive effect on the magnitude of the energy effect, since this increases the specific useful work of the expander and reduces the cost of electricity for cooling the fuel mixture at air temperatures above the optimum temperature of the mixture.

\section{CONCLUSION}

It is shown that use of circuits with EGU allows reducing fuel consumption in the considered range of outdoor temperatures by $0.65-1.2 \%$ for the pressure of $7 \mathrm{~atm}$. and $0.85-1.6 \%$ for the pressure of 13 atm. The analysis has showed that the circuit with heated gas before the expander will have the greatest energy effect at the outside air temperature up to the value corresponding to the equal values of specific fuel economy for the considered circuits with EGU and with disconnection of gas heating at higher air temperatures. The proposed method allows calculating the energy effect from the use of various circuits with EGU on existing and designed cogeneration boilers with internal combustion engines and becoming the basis of a technical and economic analysis of EGU application at cogeneration boiler houses. 


\section{Analysis of the Efficiency of Circuits using Natural Gas Additional Energy Potentials on Cogenerating Boiler Houses With Internal Combustion Engines}

\section{REFERENCES}

1. A.D.Hawkes and M. A. Leach, «Cost-effective operating strategy for residential micro-combined heat and power», Energy, 2007, vol. 32, no. 5, pp. 711-723.

2. M.Liu, Y.Shi, and F.Fang, «Combined cooling heating and power systems: A survey. Renewable Sustain», Energy, 2014, vol. 35, pp. 1-22.

3. A.Cleveland, «Power Generation with Turbo-expander», The American Society of Mechanical Engineers», 1990, vol.90, no 2, pp. 26-31.

4. H.P.Bloch and S.Claire, Turboexpander and Process Applications, Boston, Gulf Professional Publishing, 2001.

5. D.Krähenbühl, C.Zwyssig, H.Weser, and J. W. Kolar, «Theoretical and experimental results of a mesoscale electric power generation system from pressurized gas flow», IOP Publishing, Journal of Micromechanics and Microengineering, 2009, no 19, pp. 1-7.

6. H.Daneshi, Z. Khorashadi, and A. Lotfjou, «Turboexpander as a distributed generator», Power and Energy Society General Meeting Conversion and Delivery of Electrical Energy in the 21st Century. New York, 2008, pp. 1-7.

7. J. M.Taleshian, H.Rastegar, and M.Pichan, «Voltage improvement using a new control strategy for turbo-expander driving systems», Electrical Power and Energy Systems, 2015, vol. 64, pp. 1176-1184.

8. J.Peirs, D.Reynaerts, and F.Verplaetsen, «A microturbine for electric power generation. Sensors and Actuators», 2004, vol.113, pp. 86-93, 2004.

9. S.Quoilin, V.Lemort, and J.Lebrun, «Experimental study and modeling of an Organic Rankine Cycle using scroll expander», Applied Energy, 2010, vol.87, pp. 1260-1268

10. V.Lemort, S.Quoilin, C.Cuevas, and J.Lebrun, «Testing and modeling a scroll expander integrated into an Organic Rankine Cycle», Applied Thermal Engineering, 2009, vol.29, pp. 3094-3102.

11. A. Truston, «Recovering energy in gas pressure reduction», Contr. And Instrum, 1991,vol.23, no 5, pp.115-118.

12. A.Yu.Kartel, V.Ya.Gubarev, and A.G.Arzamascev, «Study of the features of expander-generator units application at cogeneration boiler-houses with internal combustion engines», Bulletin of CSTU (Chelyabinsk State Technical University),2018,no 1,pp. 20 - 27.

13. B.T.Mehdi and H.Rastegar, «Modular Modeling of Turbo-Expander Driven Generators for Power System Studies», Transactions on Electrical and Electronic Engineering, IEEJ Trans., 2009, vol.4, pp. 645-653.

14. B.T.Mehdi and H.Rastegar, «Flicker Assessment of Turbo-Expander Driven Synchronous Generator in Power Distribution», Network, Journal of Iranian Association of Electrical and Electronics Engineers, 2010, no 7, pp. 53-59.

15. T. J. Mehdi, H.Rastegar, and H.Askarian, «Modeling and Power Quality Improvement of Turbo-Expander Driving an Induction», Generator,International Journal of Energy Engineering, 2012, no 2, pp. 131-137.

16. M. A.Norouzi, J.Olamaei, and B. G. Gevork, «Compensation of voltage sag and flicker during thermal power -plant turboexpander operation by dynamic voltage restorer», International Transactions on Electrical Energy Systems, 2015,vol. 26, no 1, pp. 16-31

17. T. J.Mehdi, H.Rastegar, and M.Pichan, «Induction generator voltage improvement using a new control strategy for turbo-expander driving systems», International Journal of Electrical Power \& Energy Systems, 2015, vol.64, pp. 68-76.

18. J. D. Maddaloni, and A. M. Rowe, «Natural gas exergy recovery powering distributed hydrogen production», International Journal of Hydrogen Energy, 2007, vol.32, pp 557-566.

19. Mehdi T. J., Hasan R., A. A. Hossein, «Modeling turbo-expander systems», Simulation, 2013, vol.89, no 2, pp. 234-248

20. I.Wichterle, and R.Kobayashi, «Vapor-liquid equilibrium of methane-ethanepropane system at low temperatures and high pressures», Journal of Chemical and Engineering Data, 1972, vol.17, no 1, pp.13-18.

21. H.C.Weise, J.Jacobs, and B.H. Sage, «Phase equilibria in the hydrocarbon systems», Phase behavior in the methane-propane-n-butane system, Journal of Chemical and Engineering Data, 1970, vol.15, no 1, pp.82-91.
22. R. Aungier, Turbine aerodynamics: axial-flow and radial-flow turbine design and analysys, NewYork, The American Society of Mechanical Engineers, 2006.

23. G.V.Nimich, V.A. Mikhailov, and E.S. Bondar, Modern systems of ventilation and air conditioning, Pub.: Ivik, 2003. 